\title{
Do corticosteroids reduce postoperative pain following third molar intervention?
}

\author{
Chollathit Sugragan, Nattapong Sirintawat, Sirichai Kiattavornchareon, Lee Kian Khoo, Kumar KC, \\ Natthamet Wongsirichat \\ Department of Oral \& Maxillofacial Surgery, Faculty of Dentistry, Mahidol University, Bangkok, Thailand
}

\begin{abstract}
Background: Corticosteroids have been widely used by oral surgeons for reducing swelling caused by wisdom teeth surgery. However, they have not been proven to decrease pain. This study was aimed at analyzing previous studies pertaining to corticosteroids and pain reduction following wisdom teeth surgery.

Methods: The Science Direct, PubMed, and MEDLINE databases were searched for relevant journals according to a systematic search strategy (Patient Intervention Comparison Outcome Study). Randomized controlled trials published in English from 1998 to 2017 were extracted.

Results: Twenty-seven articles were included, with a total of 36 comparative cases. Methylprednisolone and dexamethasone were the most commonly used corticosteroids. Intramuscular injections of corticosteroids were optimal for pain reduction, regardless of the time of administration.

Conclusions: Corticosteroids can be used as an adjuvant for pain reduction following wisdom teeth surgery. Methylprednisolone and dexamethasone delivered via the intramuscular route is the best method for effective pain reduction. The ideal time for administration of corticosteroids is the preoperative period.
\end{abstract}

Keywords: Corticosteroid; Dexamethasone; Mandible; Postoperative Pain; Surgical Removal; Third Molar.

This is an Open Access article distributed under the terms of the Creative Commons Attribution Non-Commercial License (http://creativecommons.org/licenses/by-nc/4.0/) which permits unrestricted non-commercial use, distribution, and reproduction in any medium, provided the original work is properly cited.

\section{INTRODUCTION}

Impacted mandibular third molars are usually associated with concomitant pathologies that warrant surgical removal [1-3]. Surgical extraction of the mandibular third molars is the most frequent intervention in the field of oral surgery [4]. However, it is often associated with significant postoperative sequalae [5-6]. In addition to severe complications, such as dysesthesia, infection, fracture, and dry socket, patients frequently present with swelling due to inflammatory responses following surgery [7].

\section{Pain from mandibular third molar surgery}

Postoperative pain following extraction of the impacted third molars may cause severe patient distress [8]. Analgesics and anti-inflammatory drugs prescribed postoperatively should relieve pain, reduce swelling, and trismus as much as possible and improve healing without undesirable side effects. Therefore, drugs, such as corticosteroids, that exert both analgesic and anti-inflammatory effects should be used [9] for the management of postoperative discomfort.

Received: May 5, 2020 - Revised: July 5, 2020 - Accepted: August 10, 2020

Corresponding Author: Natthamet Wongsirichat, Walailak University International College of Dentistry 19th floor SM Tower, 979/42-46 Phahonyothin Road, Phaya Thai District, Bangkok 10400, Thailand

E-mail: natthamet.wo@mail.wu.ac.th and natthamet.won@mahidol.ac.th

Copyright@ 2020 Journal of Dental Anesthesia and Pain Medicine 
Table 1. Excluded studies with reasons

\begin{tabular}{lcc}
\hline \multicolumn{1}{c}{ Search strategy } & & \\
\hline \multicolumn{1}{c}{ Variable Study } & Code & Used Keywords \\
\hline Population & $\# 1$ & ("third molar" OR "third molar surgery" OR "impacted third molar") \\
Intervention & $\# 2$ & ("steroid" OR "steroids" OR "corticosteroid") \\
Comparison & $\# 3$ & ("corticosteroid" OR "placebo effect" OR "analgesic") \\
Outcome & $\# 4$ & ("pain" OR "postoperative pain") \\
Study design & $\# 5$ & Randomized controlled and controlled clinical trials \\
Search combination & & $\# 1$ AND \#2 AND \#3 AND \#4 AND \#5 \\
Database search & \\
Language & & \\
Electronic database & English & \\
\hline
\end{tabular}

Although corticosteroids have been documented to reduce swelling and trismus following wisdom teeth surgery, their role in pain reduction has not been widely reported.

\section{Comparison of types of corticosteroids}

Corticosteroids can be divided into two major groups: glucocorticoids and mineralocorticoids. Glucocorticoids have anti-inflammatory properties with minimal or no influence on the fluid or electrolyte balance; therefore, we investigated only glucocorticosteroids in this study. Hereinafter, "corticosteroids" will be used to imply "glucocorticoids" [10] in this manuscript.

This study was aimed at analyzing the efficacy of corticosteroids in pain management after mandibular third molar surgery through a review of several published scientific studies. We also aimed to obtain knowledge about more effective adjuvant analgesic methods.

\section{METHODS}

\section{Trial selection}

The search methodology was organized using a systematic search strategy (Patient Intervention Comparison Outcome Study), as shown in Table 1. The Scopus, PubMed, and MEDLINE databases were searched from 1998 to 2017 (20 years). We started the study with a suitable title on 2018 and finished it by the end of that year (2018).

The keywords used to explore the databases were: "third molar" OR "third molar surgery" OR "impacted third molar" AND "steroid" OR "steroids" OR "corticosteroid" AND "pain" OR "postoperative pain."

Two separate reviewers performed the literature search, and the sifting process was ideally used. Both reviewers agreed on the best practice guidelines in conducting systematic reviews.

\section{Study criteria}

Studies were included if all of the following eligibility criteria were met:

1. Randomized clinical trial (RCT) or controlled clinical trial (CCT)

2. Involving the surgical removal of an impacted mandibular third molar

3. Including corticosteroids as intervention

4. Pain measured on the visual analogue scale (VAS)

\section{Data extraction}

As presented in Table 2 [11-37], data extracted from studies were:

1. Authors and year of publication

2. Study design, number of subjects, and mean age

3. Mean duration of surgery

4. Type of corticosteroid

5. Corticosteroid dosage and route of administration

6. Timing of corticosteroid administration 
Table 2. Articles selected for the analysis from 1998 to 2017

\begin{tabular}{|c|c|c|c|c|c|c|c|c|c|c|c|c|}
\hline No. & Year & Author & Sample size & $\begin{array}{l}\text { Mean age } \\
\text { (years) }\end{array}$ & Group & N & Steroid & Dose (mg) & Route & Time & $\begin{array}{l}\text { Duration of assessment } \\
\text { (day) }\end{array}$ & $\begin{array}{c}\text { pain } \\
\text { assessment }\end{array}$ \\
\hline \multirow[t]{2}{*}{1.} & 2017 & Chugh et al. [25] & 60 & 29.7 & A & 17 & Control & 0 & SM & pre-op & $1,3,4,7$ & VAS \\
\hline & & & & & B & 23 & Dexamethasone & 8 & SM & pre-op & & VAS \\
\hline \multirow[t]{2}{*}{2.} & 2017 & Al-Dajani [30] & 32 & $N R$ & A & 32 & Dexamethasone & $0.1 \mathrm{mg} / \mathrm{kg}$ & $\mathrm{IM}$ & pre-op & $2,4,6$ & VAS \\
\hline & & & & & B & 32 & Control & 0 & $\mathrm{IM}$ & pre-op & & TAC \\
\hline \multirow[t]{3}{*}{3.} & 2017 & Lim \& Ngeow [31] & 65 & 25 & A & 22 & Control & 0 & SM & pre-op & $1,2,5,7$ & VAS \\
\hline & & & & & B & 22 & Dexamethasone & 4 & SM & pre-op & & VAS \\
\hline & & & & & C & 21 & Methylprednisolone & 40 & SM & pre-op & & VAS \\
\hline \multirow[t]{3}{*}{4.} & 2016 & Saravanan et al. [29] & 60 & NR & A & 20 & Control & 0 & No & No & $0,1,3,7$ & VAS \\
\hline & & & & & B & 20 & Dexamethasone & 8 & IV & pre-op & & VAS \\
\hline & & & & & C & 20 & Dexamethasone & 8 & SM & pre-op & & \\
\hline \multirow[t]{2}{*}{5.} & 2014 & Chaudhary et al. [11] & 200 & 20.8 & A & 100 & Dexamethasone & 4 & IV & pre-op & $1,2,7$ & VAS \\
\hline & & & & & B & 100 & Dexamethasone & 8 & PO & pre-op & & TAC \\
\hline \multirow[t]{3}{*}{6.} & 2014 & Ilhan et al. [22] & 60 & NR & A & 20 & Tenoxicam & $x$ & $x$ & $x$ & 1 (q 1 h) & VAS \\
\hline & & & & & B & 20 & methylprednisolone & 80 & IV & pre-op & & \\
\hline & & & & & C & 20 & Control & 0 & IV & pre-op & & \\
\hline \multirow[t]{2}{*}{7.} & 2014 & Selvaraj et al. [26] & 10 & NR & A & 5 & Methylprednisolone & 40 & IM (massetter) & pre-op & $1,2,3$ & VAS \\
\hline & & & & & B & 5 & Methylprednisolone & 40 & IM(gluteal) & pre-op & & \\
\hline \multirow[t]{2}{*}{8.} & 2013 & Alcântara et al. [12] & 16 & 20.3 & $A$ & 16 & Dexamethasone & 8 & IV & pre-op & $1,2,3$ & VAS \\
\hline & & & & & B & 16 & Methylprednisolone & 40 & $\mathrm{PO}$ & pre-op & & TAC \\
\hline \multirow[t]{4}{*}{9.} & 2013 & Mehra et al. [18] & 80 & NR & A & 20 & Control & 0 & IV & intra-op & $1,2,3,7$ & VAS \\
\hline & & & & & B & 20 & Ibuprofen & $x$ & $x$ & $x$ & & \\
\hline & & & & & C & 20 & Dexamethasone & 8 & IV & intra-op & & \\
\hline & & & & & D & 20 & $\begin{array}{c}\text { Dexamethasone/ } \\
\text { ibuprofen }\end{array}$ & $x$ & $x$ & $x$ & & \\
\hline \multirow[t]{2}{*}{10.} & 2013 & Warraich et al. [20] & 100 & 26.9 & A & 50 & Dexamethasone & 4 & SM & pre-op & 2,10 & VAS \\
\hline & & & & & B & 50 & Control & 0 & № & No & & \\
\hline \multirow[t]{2}{*}{11.} & 2013 & Marques et al. [23] & 60 & 23.44 & A & 30 & Betamethasone & 12 & SM & post-op & $1,2,3$ & VAS \\
\hline & & & & & B & 30 & Control & 0 & SM & post-op & & \\
\hline \multirow[t]{2}{*}{12.} & 2012 & Acham et al. [19] & 16 & 23 & A & 8 & Methylprednisolone & $\begin{array}{l}\text { 40-80 (weight } \\
\text { dependent) }\end{array}$ & PO & pre-op & $1,2,3,4,5,6,7$ & VAS \\
\hline & & & & & B & 8 & Control & 0 & $\mathrm{PO}$ & pre-op & & \\
\hline \multirow[t]{4}{*}{13.} & 2012 & Simone et al. [24] & 54 & NR & A & 20 & Dexamethasone & 8 & $\mathrm{PO}$ & pre-op & $0,1,2,4,7$ & VAS \\
\hline & & & & & B & 14 & Control & 0 & PO & pre-op & & TAC \\
\hline & & & & & C & 20 & Diclofenac & $x$ & $x$ & $x$ & & \\
\hline & & & & & C & 20 & Methylprednisolone & 40 & SM & pre-op & & VAS \\
\hline \multirow[t]{2}{*}{14.} & 2011 & Klongnoi et al. [13] & 20 & 21 & A & 10 & Dexamethasone & 8 & $\mathrm{IM}$ & pre-op & $1,2,7$ & VAS \\
\hline & & & & & B & 10 & Control & 0 & $\mathrm{M}$ & pre-op & & TAC \\
\hline \multirow[t]{2}{*}{15.} & 2011 & Boonsiriseth et al. [14] & 20 & 20 & A & 10 & Dexamethasone & 8 & $\mathrm{IM}$ & post-op & $1,2,3,4,5,6,7$ & VAS \\
\hline & & & & & B & 10 & Dexamethasone & 8 & $\mathrm{PO}$ & post-op & & TAC \\
\hline \multirow[t]{3}{*}{16.} & 2011 & Majid [16] & 33 & NR & A & 11 & Control & 0 & No & No & $0,1,3,7$ & VAS \\
\hline & & & & & B & 11 & Dexamethasone & 4 & $\mathrm{IM}$ & post-op & & VAS \\
\hline & & & & & C & 11 & Dexamethasone & 4 & SM & post-op & & \\
\hline \multirow[t]{3}{*}{17.} & 2011 & Antunes et al. [21] & 67 & 21 & A & 18 & Dexamethasone & 8 & IM & pre-op & $1,3,7$ & VAS \\
\hline & & & & & B & 20 & Dexamethasone & 8 & PO & pre-op & & TAC \\
\hline & & & & & C & 22 & Control & 0 & No & No & & \\
\hline \multirow[t]{3}{*}{18.} & 2010 & Majid \& Mahmood [17] & 30 & 27 & A & 10 & Control & 0 & No & No & $0,1,3,7$ & VAS \\
\hline & & & & & B & 10 & Dexamethasone & 4 & IM & post-op & & VAS \\
\hline & & & & & C & 10 & Dexamethasone & 4 & SM & post-op & & \\
\hline
\end{tabular}




\begin{tabular}{|c|c|c|c|c|c|c|c|c|c|c|c|c|}
\hline \multirow[t]{3}{*}{19.} & 2010 & Kang et al. [27] & 60 & NR & $A$ & 96 & Control & 0 & No & No & $1,2,3,4,5,6$ & VAS \\
\hline & & & & & B & 60 & Prednisolone & 10 & PO & pre-op & & \\
\hline & & & & & C & 64 & Prednisolone & 20 & PO & pre-op & & \\
\hline \multirow[t]{5}{*}{20.} & 2009 & Chopra et al. [28] & 150 & 28 & $A$ & 30 & Control & 0 & PO & pre-op & $1,3,5,7$ & VAS \\
\hline & & & & & B & 30 & Paracetamol & $x$ & $x$ & $x$ & & \\
\hline & & & & & C & 30 & Serratipeptidase & $x$ & $x$ & $x$ & & \\
\hline & & & & & D & 30 & |buprofen & $x$ & $x$ & $x$ & & \\
\hline & & & & & E & 30 & Betamethasone & 0.5 & PO & post-op & & \\
\hline \multirow[t]{2}{*}{21.} & 2008 & $\begin{array}{l}\text { Vegas-Bustamante } \\
\text { et al. [15] }\end{array}$ & 40 & 25 & A & 20 & Methylprednisolone & 40 & $\mathrm{IM}$ & post-op & $1,2,3$ & VAS \\
\hline & & & & & B & 20 & Control & 0 & № & No & & \\
\hline \multirow[t]{3}{*}{22.} & 2008 & Zandi [32] & 22 & $N R$ & $A$ & 11 & Drain & 0 & No & No & 2,7 & 4 point scale \\
\hline & & & & & B & 11 & Dexamethasone & 8 & IV & pre-op & & \\
\hline & & & & & C & 22 & Control & 0 & No & № & & \\
\hline \multirow[t]{3}{*}{23.} & 2006 & Buyukkurt et al. [36] & 45 & 22.87 & $A$ & 15 & Prednisolone & 25 & $\mathrm{IM}$ & post-op & 1 (q 1 hr.) & VAS \\
\hline & & & & & B & 15 & $\begin{array}{l}\text { prednisolone/ } \\
\text { diclofenac }\end{array}$ & 25 & $\mathrm{IM}$ & post-op & & \\
\hline & & & & & C & 15 & Control & 0 & $\mathrm{IM}$ & post-op & & \\
\hline \multirow[t]{4}{*}{24.} & 2005 & Graziani et al. [33] & 43 & 24 & A & 14 & Dexamethasone & 4 & $\begin{array}{l}\text { endo-alveolar } \\
\text { powder }\end{array}$ & intraop & 2,7 & VAS \\
\hline & & & & & B & 14 & Dexamethasone & 10 & $\begin{array}{l}\text { endo-alveolar } \\
\text { powder }\end{array}$ & intraop & & VAS \\
\hline & & & & & C & 15 & Dexamethasone & 10 & SM & intraop & & VAS \\
\hline & & & & & D & 43 & Control & 0 & No & № & & \\
\hline \multirow[t]{4}{*}{25.} & 2004 & Moore et al. [37] & 29 & 22.8 & $A$ & 8 & Control & 0 & PO/V & $\begin{array}{l}\text { pre-op/ } \\
\text { intra-op }\end{array}$ & $1,2,3,7$ & VAS \\
\hline & & & & & B & 5 & Rofecoxib/placebo & PO/V & $\begin{array}{l}\text { pre-op/ } \\
\text { intra-op }\end{array}$ & & & \\
\hline & & & & & C & 9 & $\begin{array}{c}\text { Placebo/ } \\
\text { dexamethasone }\end{array}$ & 10 & PO/V & $\begin{array}{l}\text { pre-op/ } \\
\text { intra-op }\end{array}$ & & \\
\hline & & & & & D & 7 & $\begin{array}{c}\text { Rofecoxib/ } \\
\text { dexamethasone }\end{array}$ & PO/V & pre-op/intra-op & & & \\
\hline \multirow[t]{2}{*}{26.} & 2003 & Üstün et al. [34] & 20 & 21.9 & $A$ & 20 & Methylprednisolone & $1.5 \mathrm{mg} / \mathrm{kg}$ & IV & pre-op & $1,2,3,4,5,6,7$ & VAS \\
\hline & & & & & B & 20 & Methylprednisolone & $3 \mathrm{mg} / \mathrm{kg}$ & IV & pre-op & & TAC \\
\hline \multirow[t]{5}{*}{27.} & 1998 & Claseman et al. [35] & 34 & NR & A & 8 & Control & 0 & IV & pre-op & 1 (q 2 h) & VAS \\
\hline & & & & & B & 9 & Ketorolac & 30 & IV & pre-op & & \\
\hline & & & & & C & 8 & Dexamethasone & 8 & IV & pre-op & & \\
\hline & & & & & D & 9 & Ketorolac & 30 & IV & pre-op & & \\
\hline & & & & & & & Dexamethasone & 8 & IV & pre-op & & \\
\hline
\end{tabular}

REMARK: NR, no report; $X$, Data were not collected; IM, intramuscular; IV, intravenous; SM, submucosal; PO, per oral.

7. Time of pain assessment

8. Method of pain assessment, mean VAS score, and p-values

\section{Statistical Analysis}

Descriptive analysis and Spearman correlation coefficients were used to analyze the correlation.

\section{RESULTS}

The initial search yielded 99 articles. After title screening, 36 articles were selected for abstract screening. Subsequently, seven studies were excluded for following reasons:

1. Unclear data on the patient selection, treatment, route of administration, dose, or surgical procedure 


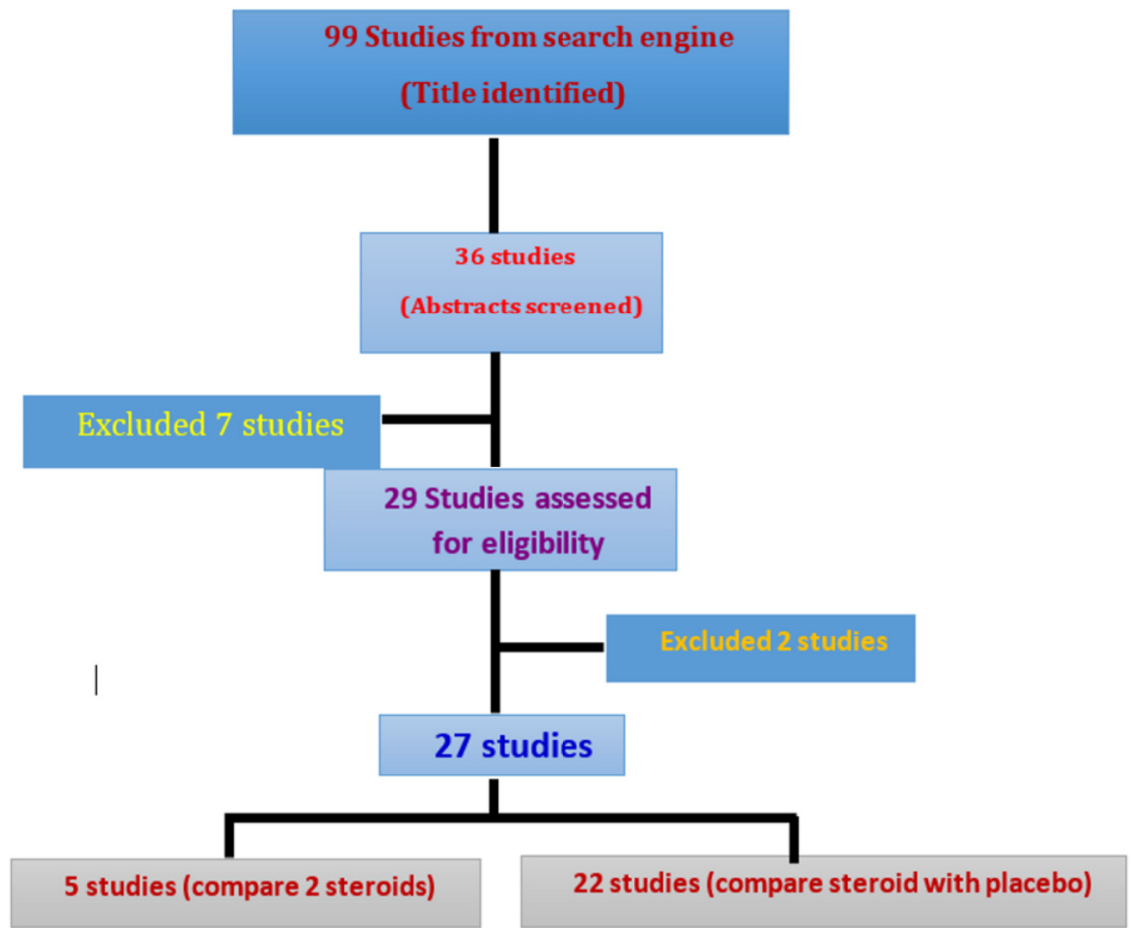

Fig. 1. The number of articles extracted from the search that were excluded or included in this analysis are shown in a flowchart.

2. Improper evaluation of pain or inadequate information of pain outcomes

3. Comparison of corticosteroids with other drugs Two articles were later excluded because the study had not used VAS for pain assessment.

Finally, 27 articles were chosen for the analysis. Fig. 1 illustrates a flow chart of the 27 case studies that were selected. The effects of varying concentrations of corticosteroids compared to placebo were assessed in 22 studies. The other five previous studies compared types of corticosteroids in terms of the VAS score after surgical removal of the mandibular third molar (Table 2). The corticosteroids used were dexamethasone, methylprednisolone, betamethasone, prednisolone, and placebo/ dexamethasone in $64 \%, 19 \%, 6 \%, 8 \%$, and $3 \%$, respectively.

Postoperative pain reduced significantly in patients who took corticosteroids in comparison with those who took a placebo drug. When methylprednisolone and dexamethasone were compared, no significant difference in postoperative pain was found (Table 3). These results suggested that all corticosteroids (glucocorticoids) offered the same efficacy in pain reduction following surgical removal of the mandibular third molars. This study also focused on articles that reported no steroid treatment or placebo. There were 31 case studies with four features: steroid, dose, route, and time.

We applied one hot methodology and Spearman correlation to determine the key factors contributing to pain reduction and found that the route of drug delivery (max of corr. $=0.3727$ ) is the most important factor, followed by the type of steroid ( $\max$ of corr. $=0.1667$ ) and time $(\max$ of corr. $=0.1373$; Table 4$)$.

The percentages of pain reduction in patients administered with corticosteroids intramuscularly, intravenously, and via other routes (submucosal, PO, and endo-alveolar powder) were $100 \%, 83.33 \%$, and $50 \%$, respectively.

Methylprednisolone, dexamethasone, betamethasone, and prednisolone reduced pain in $75 \%$ (three of four), $72.72 \%$ (16 of 22 ), $50 \%$ (one of two), and 33\% (one of three) of patients, respectively.

The optimal administration timing for corticosteroids was postoperative $(77.77 \%$, seven of nine), followed by 
Table 3. Studies that compared different types or doses of steroids

\begin{tabular}{ccccccc}
\hline Author & year & No of study & Type of Steroid and dose (mg) & Route & Time & Result \\
\hline Ma'aita \& Alwrikat [2] & 2000 & 16 & $\begin{array}{c}\text { Dexamethasone (8) vs. } \\
\text { Methylprednisolone (40) }\end{array}$ & IV vs. P0 & pre-op & ND \\
Laureano Filho et al. [4] & 2008 & 10 & Dexamethasone (8) & IM vs. P0 & post-op & ND \\
Majid [16] & 2011 & 5 & Methylprednisolone (40) & IM (masseter vs. gluteal) & pre-op & ND \\
McCoy [1] & 2012 & 100 & Dexamethasone (4 vs. 8) & IV vs. PO & pre-op & ND \\
Simone [24] & 2013 & 20 & Methylprednisolone & IV & pre-op & ND \\
\end{tabular}

REMARK: vs, versus; IM, intramuscular; IV, intravenous; PO, per oral; pre-op, preoperatively; post-op, postoperatively; ND, No difference.

Table 4. Spearman correlation for studies on non-steroid use

\begin{tabular}{|c|c|c|c|c|c|c|c|c|c|c|c|c|c|}
\hline Result & 1.0000 & -0.0997 & 0.1667 & 0.0598 & 0.2409 & 0.3727 & 0.1634 & 0.1859 & 0.2619 & 0.0997 & 0.2602 & 0.1373 & 0.0671 \\
\hline Betamethasone & -0.0997 & 1.0000 & -0.4106 & -0.1011 & -0.0860 & -0.1418 & -0.1287 & 0.2037 & 0.0997 & -0.0690 & -0.1152 & 0.1213 & -0.0255 \\
\hline Dexamethasone & 0.1667 & -0.4106 & 1.0000 & -0.6018 & -0.5118 & 0.1755 & 0.1335 & -0.4062 & 0.0147 & 0.1680 & 0.2805 & -0.0606 & -0.1520 \\
\hline $\begin{array}{l}\text { Methyl- } \\
\text { prednisolone }\end{array}$ & 0.0598 & -0.1011 & -0.6018 & 1.0000 & -0.1260 & -0.2079 & 0.0550 & 0.0550 & 0.1461 & -0.1011 & -0.1688 & 0.0342 & 0.1559 \\
\hline Prednisolone & 0.2409 & -0.0860 & -0.5118 & -0.1260 & 1.0000 & 0.0842 & -0.1604 & 0.3920 & -0.2259 & -0.0860 & -0.1435 & 0.0310 & 0.0778 \\
\hline $\mathrm{IM}$ & 0.3727 & -0.1418 & 0.1755 & -0.2079 & 0.0842 & 1.0000 & -0.2646 & -0.2646 & -0.3727 & -0.1418 & -0.2368 & 0.3345 & 0.1300 \\
\hline IV & 0.1634 & -0.1287 & 0.1335 & 0.0550 & -0.1604 & -0.2646 & 1.0000 & -0.2400 & -0.3381 & -0.1287 & 0.2292 & -0.3133 & 0.1164 \\
\hline PO & 0.1859 & 0.2037 & -0.4062 & 0.0550 & 0.3920 & -0.2646 & -0.2400 & 1.0000 & -0.3381 & -0.1287 & -0.2148 & -0.1335 & 0.2805 \\
\hline SM & 0.2619 & 0.0997 & 0.0147 & 0.1461 & -0.2259 & -0.3727 & -0.3381 & -0.3381 & 1.0000 & -0.1812 & -0.1150 & 0.1667 & -0.0671 \\
\hline $\begin{array}{l}\text { Endo- } \\
\text { alveolar powder }\end{array}$ & 0.0997 & -0.0690 & 0.1680 & -0.1011 & -0.0860 & -0.1418 & -0.1287 & -0.1287 & -0.1812 & 1.0000 & 0.5988 & -0.1680 & -0.2894 \\
\hline $\begin{array}{l}\text { Intra- } \\
\text { operatively }\end{array}$ & 0.2602 & -0.1152 & 0.2805 & -0.1688 & -0.1435 & -0.2368 & 0.2292 & -0.2148 & -0.1150 & 0.5988 & 1.0000 & -0.2805 & -0.4832 \\
\hline $\begin{array}{l}\text { Post- } \\
\text { operatively }\end{array}$ & 0.1373 & 0.1213 & -0.0606 & 0.0342 & 0.0310 & 0.3345 & -0.3133 & -0.1335 & 0.1667 & -0.1680 & -0.2805 & 1.0000 & -0.7084 \\
\hline \multirow[t]{2}{*}{$\begin{array}{l}\text { Pre- } \\
\text { operatively }\end{array}$} & 0.0671 & -0.0255 & -0.1520 & 0.1559 & 0.0778 & 0.1300 & 0.1164 & 0.2805 & -0.0617 & -0.2894 & -0.4832 & -0.7084 & 1.0000 \\
\hline & 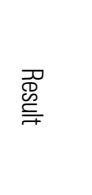 & 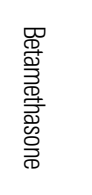 & 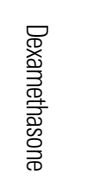 & 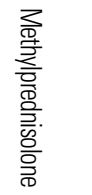 & 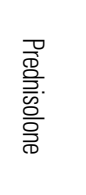 & $\bar{z}$ & $z$ & 7 & $\stackrel{\text { so }}{S}$ & 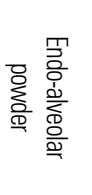 & 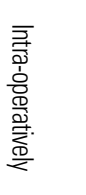 & 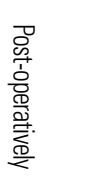 & 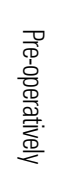 \\
\hline
\end{tabular}

preoperative $(70.58 \%, 12$ of 15$)$ and intraoperative $(40 \%)$.

In Fig. 2 the decision flow chart shows three factors that influenced the effectiveness of corticosteroids for reducing pain (route, type, and timing). This study found the intramuscular route to be extremely effective for reducing pain, consistent with previous studies. We also found five studies that documented $100 \%$ efficacy of corticosteroids in pain reduction and four studies that reported no effect in pain reduction.

However, one major limitation of the present study was the extremely small sample size, including six of nine studies that showed $100 \%$ effectiveness or no effect at all for reducing pain. Although oral prednisolone was assessed in two case studies, the timing of drug administration was not considered.

From the decision tree, we found three studies with a $50 \%$ probability of effective reduction in pain with any corticosteroid administered via the endo-alveolar route, dexamethasone via the oral route, and any corticosteroid via the intravenous route intraoperatively. Meanwhile, dexamethasone via a submucosal injection postoperatively as effectively reduced pain as a submucosal injection preoperatively at the same dose. 


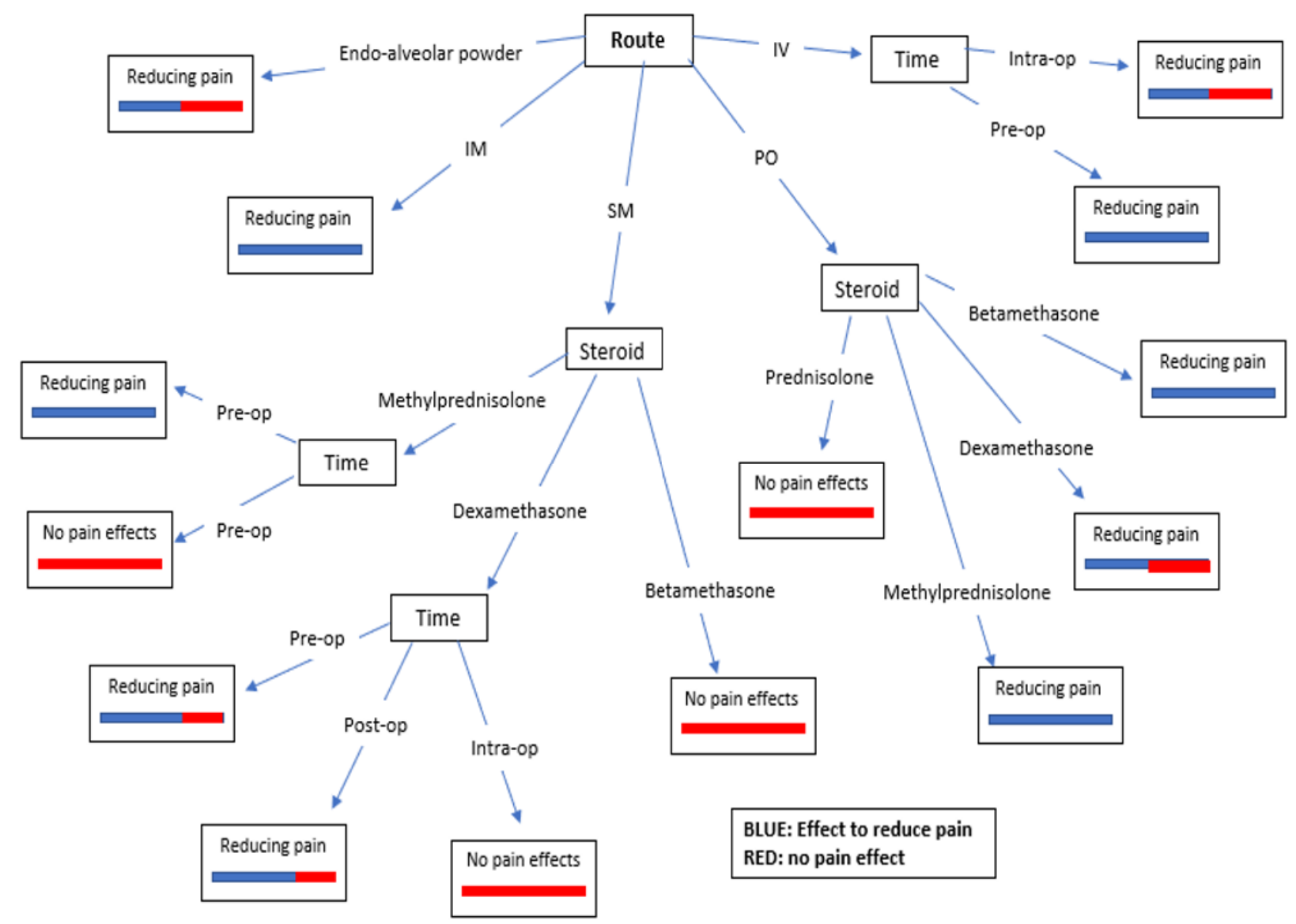

Fig. 2. The decision tree included three factors affecting pain reduction (route, type of steroid, and timing).

\section{DISCUSSION}

Patients are usually afraid of having their wisdom teeth removed because of the fear of pain. Postoperative pain could be managed with analgesics, which reduce pain to a bearable level. Although the role of corticosteroids has mainly been of reducing postoperative swelling and limited mouth opening, corticosteroids also have analgesic properties if administered at the right time of the procedure and via an ideal route of drug administration.

Corticosteroids act by suppressing each phase of the initial inflammatory response, thereby decreasing cellular permeability and capillary dilatation by inhibiting the production of vasoactive substances and diminishing the amount of cytokines [38,39]. Furthermore, the generation of prostaglandin is repressed by corticosteroids, resulting in an analgesic effect $[40,41]$.

We reviewed 27 previous articles (36 study groups) reporting RCTs involving corticosteroids in comparison with placebo (31 study groups) or comparison of different corticosteroids (five study groups). This study found dexamethasone and methylprednisolone to be the most used corticosteroids because of their pure glucocorticoid nature with no mineralocorticoid effects. These corticosteroids have been used widely in dento-alveolar surgery with minimal adverse effects on leukocyte chemotaxis; their half-life is of an intermediate duration $(18-36 \mathrm{~h})$ and potency greater than that of hydrocortisone[42].

There was no significant difference in postoperative pain score across corticosteroid types and doses. Chaudhary et al. [11] found good pain relief with the use of dexamethasone via oral or intravenous administration. Their study found no significant difference in post- 
operative pain between 4 and $8 \mathrm{mg}$ of intravenous dexamethasone.

Boonsiriseth et al. [14] reported that the VAS scores for pain assessment showed no significant difference between $8 \mathrm{mg}$ intramuscular and oral dexamethasone following impacted third molar extraction.

An 8-mg single dose of preoperative intramuscular dexamethasone for impacted mandibular third molar surgery was used in the study by Klongnoi et al., which revealed no significant difference between dexamethasone and placebo in pain assessment on VAS [13].

Moreover, a study by Alcântara et al. [12] showed no statistically significant difference in pain scores between $8 \mathrm{mg}$ intravenous dexamethasone and $40 \mathrm{mg} \mathrm{PO}$ methylprednisolone following surgical third molar removal. There is no statistically significant difference between the intrabuccal approach for a masseteric muscle injection and gluteal muscle injection of methylprednisolone [26]. Simultaneously, a study by Üstün et al. investigated pain between the groups of 1.5 and 3 $\mathrm{mg} / \mathrm{kg}$ of methylprednisolone via an intravenous injection and reported no statistically significant difference between the two doses [34]. Postoperative pain was relieved with corticosteroids compared to placebo in 21 of 31 cases $(67.74 \%)$ and using corticosteroids via intramuscular injections could be the most effective drug delivery administration for postoperative pain control when compared to another administration via another route.

A single dose of pre- or postoperative intramuscular administration [13] can deliver stable plasma drug concentrations and extended anti-inflammatory activity. Masseter and deltoid muscle injections are the most effective.

From this study, the intravenous injection of corticosteroids preoperatively provides decreased postoperative pain better than intraoperative or postoperative intravenous injections. The preoperative intravenous injection provides immediate therapeutic drug concentrations in the blood before actual surgical trauma [43]. Nonetheless, the distinct disadvantage of both intramuscular and intra- venous injections is an additional discomfort or pain at the injection site.

In the scholarly articles reviewed, the use of corticosteroids aided in exerting an additional analgesic effect. However, the use of analgesics for pain control is still recommended.

It is difficult to draw finite conclusions from all these studies because of the varying skills of surgeons and depth and angulation of the wisdom teeth. Furthermore, postoperative pain measurements were performed in different time periods. The objective and subjective factors, such as degree of surgical trauma, duration of surgery, and experience of the surgeon, as well as the anxiety, pain tolerance, pain expectation, or analgesic drug use of the patient can affect the outcome of pain evaluation following impacted third molar surgery [44]. The sociocultural background may also affect the pain outcome, tolerance, and expectations, which could differ among individuals from developed countries to those from underdeveloped nations.

Although our study found many articles that mentioned pain reduction with corticosteroids, the exact mechanism for this effect is not yet defined. The authors assume that corticosteroids work by reducing prostaglandin synthesis, which suppresses the vascular events that lead to the cardinal signs of inflammation, thereby reducing swelling, redness, heat, and pain.

Steroids are an analgesic adjuvant. They have shown analgesic properties in some painful situations, although their use is mostly outside pain management. With different mechanisms of action, there are many names of these drugs, such as secondary analgesics, co-analgesics, auxiliary analgesics, and non-indication drugs. Therefore, most steroids are only adjuvant agents for preventing inflammation and edema of the oral soft tissue, which contribute to the development of pain.

In conclusion, corticosteroids can have analgesic properties but are not analgesic drugs because of the indirect analgesic effects. They can be used in combination with analgesics to reduce inflammatory symptoms, including pain. Methylprednisolone and dexamethasone 
are the suggested drugs that can effectively decrease pain after impacted mandibular third molar surgery. The intramuscular and intravenous routes are the most effective for pain reduction. The perfect timing for injection to obtain maximum benefit from corticosteroids for pain reduction is the preoperative period.

\section{AUTHOR ORCGIIS}

Chollathit Sugragan: https://orcid.org/0000-0001-8656-1682

Nattapong Sirintawat: https://orcid.org/0000-0002-6441-5243

Sirichai Kiattavornchareon: https://orcid.org/0000-0001-6766-9188

Lee Kian Khoo: https://orcid.org/0000-0003-4135-1563

Kumar KC: https://orcid.org/0000-0001-9620-7388

Natthamet Wongsirichat: https://orcid.org/0000-0003-3005-2680

\section{AUHOR GONHRIBIONS}

Chollathit Sugragan: Data curation, Investigation, Software

Nattapong Sirintawat: Conceptualization, Data curation, Funding acquisition, Investigation

Sirichai Kiattavornchareon: Conceptualization, Methodology, Project administration, Supervision, Visualization

Lee Kian Khoo: Methodology, Visualization, Writing - review \& editing Kumar KC: Investigation, Methodology, Resources, Visualization Natthamet Wongsirichat: Conceptualization, Supervision, Writing review \& editing

ACKNOWLEDGMENTS: The authors would like to thank the staff, colleagues, and dental assistants, including co-workers, at the Department of Oral and Maxillofacial Surgery, Faculty of Dentistry, Mahidol University. Finally, the authors would like to thank Christian Estacio for editing and revising the language of this manuscript.

DECLARATION OF PATIENT CONSENT: No patient consent was required because of the retrospective study design. FUNDING, CONFLICTS OF INTEREST, ETHICAL APPROVAL FUNDING AND SPONSORSHIP: This research study did not receive funding from any sponsor or scholarship CONFLICTS OF INTEREST: The authors declared a conflict of interest.

ETHICS APPROVAL FOR CLINICAL STUDY: This study did not require approval from the Faculty of Dentistry/Faculty of Pharmacy, Mahidol University, Institutional Review
Board (MU-DT/PY-IRB), because of the retrospective study design.

\section{REFERENCES}

1. McCoy JM. Complications of retention: pathology associated with retained third molars. Atlas Oral Maxillofac Surg Clin North Am 2012; 20: 177-95.

2. Ma'aita J, Alwrikat A. Is the mandibular third molar a risk factor for mandibular angle fracture? Oral Surg Oral Med Oral Pathol Oral Radiol Endod 2000; 89: 143-6.

3. Campbell JH. Pathology associated with the third molar. Oral Maxillofac Surg Clin North Am 2013; 25: 1-10.

4. Laureano Filho JR, Maurette PE, Allais M, Cotinho M, Fernandes C. Clinical comparative study of the effectiveness of two dosages of dexamethasone to control postoperative swelling, trismus and pain after the surgical extraction of mandibular impacted third molars. Med Oral Patol Oral Cir Bucal 2008; 13: E129-32.

5. Dhariwal DK, Goodey R, Shepherd JR. Trends in oral surgery in England and Wales 1991-2000. Br Dent J 2002; 192: 639-45.

6. Mercier P, Precious D. Risks and benefits of removal of impacted third molars: a critical review of the literature. Int J Oral Maxillofac Surg 1992; 21: 17-27.

7. Alexander RE, Throndson RR. A review of perioperative corticosteroid use in dentoalveolar surgery. Oral Surg Oral Med Oral Pathol Oral Radiol Endod 2000; 90: 406-15.

8. Chaparro-Avendaño AV, Pérez-García S, Valmaseda-Castellón E, Berini-Aytés L, Gay-Escoda C. Morbidity of third molar extraction in patients between 12 and 18 years of age. Med Oral Patol Oral Cir Bucal 2005; 10: 422-31.

9. Seymour RA, Walton JG. Pain control after third molar surgery. Int J Oral Surg 1984; 13: 457-85.

10. Ngeow WC, Lim D. Do corticosteroids still have a role in the management of third molar surgery? Adv Ther 2016; 33: $1105-39$

11. Chaudhary PD, Rastogi S, Gupta P, Niranjanaprasad Indra B, Thomas R, Choudhury R. Pre-emptive effect of 
dexamethasone injection and consumption on post-operative swelling, pain, and trismus after third molar surgery. a prospective, double blind and randomized study. J Oral Biol Craniofac Res 2015; 5: 21-7.

12. Alcântara CEP, Falci SGM, Oliveira-Ferreira F, Santos CRR, Pinheiro MLP. Pre-emptive effect of dexamethasone and methylprednisolone on pain, swelling, and trismus after third molar surgery: a split-mouth randomized triple-blind clinical trial. Int J Oral Maxillofac Surg 2014; 43: 93-8.

13. Klongnoi B, Kaewpradub P, Boonsiriseth K, Wongsirichat N. Effect of single dose preoperative intramuscular dexamethasone injection on lower impacted third molar surgery. Int J Oral Maxillofac Surg 2012; 41: 376-9.

14. Boonsiriseth K, Klongnoi B, Sirintawat N, Saengsirinavin C, Wongsirichat N. Comparative study of the effect of dexamethasone injection and consumption in lower third molar surgery. Int J Oral Maxillofac Surg 2012; 41: 244-7.

15. Vegas-Bustamante E, Micó-Llorens J, Gargallo-Albiol J, Satorres-Nieto M, Berini-Aytes L, Gay-Escoda C. Efficacy of methylprednisolone injected into the masseter muscle following the surgical extraction of impacted lower third molars. Int J Oral Maxillofac Surg 2008; 37: 260-3.

16. Majid OW. Submucosal dexamethasone injection improves quality of life measures after third molar surgery: a comparative study. J Oral Maxillofac Surg 2011; 69: 2289-97.

17. Majid OW, Mahmood WK. Effect of submucosal and intramuscular dexamethasone on postoperative sequelae after third molar surgery: comparative study. Br J Oral Maxillofac Surg 2011; 49: 647-52.

18. Mehra P, Reebye U, Nadershah M, Cottrell D. Efficacy of anti-inflammatory drugs in third molar surgery: a randomized clinical trial. Int J Oral Maxillofac Surg 2013; 42: $835-42$

19. Acham S, Klampfl A, Truschnegg A, Kirmeier R, Sandner-Kiesling A, Jakse N. Beneficial effect of methylprednisolone after mandibular third molar surgery: a randomized, double-blind, placebo-controlled split-mouth trial. Clin Oral Investig 2013; 17: 1693-700.

20. Warraich R, Faisal M, Rana M, Shaheen A, Gellrich NC, Rana M. Evaluation of postoperative discomfort following third molar surgery using submucosal dexamethasone-a randomized observer blind prospective study. Oral Surg Oral Med Oral Pathol Oral Radiol 2013; 116: 16-22.

21. Antunes AA1, Avelar RL, Martins Neto EC, Frota R, Dias E. Effect of two routes of administration of dexamethasone on pain, edema, and trismus in impacted lower third molar surgery. Oral Maxillofac Surg 2011; 15: 217-23.

22. Ilhan O, Agacayak KS, Gulsun B, Koparal M, Gunes N. A comparison of the effects of methylprednisolone and tenoxicam on pain, edema, and trismus after impacted lower third molar extraction. Med Sci Monit 2014; 20: 147-52.

23. Marques J, Pié-Sánchez J, Figueiredo R, Valmaseda-Castellón E, Gay-Escoda C. Effect of the local administration of betamethasone on pain, swelling and trismus after impacted lower third molar extraction. A randomized, triple blinded, controlled trial. Med Oral Patol Oral Cir Bucal 2014; 19: e49-54.

24. Simone JL, Jorge WA, Horliana ACRT, Canaval TG, Tortamano IP. Comparative analysis of preemptive analgesic effect of dexamethasone and diclofenac following third molar surgery. Braz Oral Res 2013; 27: 266-71.

25. Chugh A, Singh S, Mittal Y, Chugh V. Submucosal injection of dexamethasone and methylprednisolone for the control of postoperative sequelae after third molar surgery: randomized controlled trial. Int J Oral Maxillofac Surg 2018; 47: 228-33.

26. Selvaraj L, Rao SH, Lankupalli AS. Comparison of efficacy of methylprednisolone injection into masseter muscle versus gluteal muscle for surgical removal of impacted lower third molar. J Maxillofac Oral Surg 2014; 13: 495-8.

27. Kang SH, Choi YS, Byun IY, Kim MK. Effect of preoperative prednisolone on clinical postoperative symptoms after surgical extractions of mandibular third molars. Aust Dent J 2010; 55: 462-7.

28. Chopra D, Rehan HS, Mehra P, Kakkar AK. A randomized, double-blind, placebo-controlled study comparing the efficacy and safety of paracetamol, serratiopeptidase, ibuprofen and betamethasone using the dental impaction pain model. Int J Oral Maxillofac Surg 2009; 38: 350-5. 29. Saravanan K, Kannan R, John RR, Nantha Kumar CN. 
A single pre operative dose of sub mucosal dexamethasone is effective in improving post operative quality of life in the surgical management of impacted third molars: a comparative randomised prospective study. J Maxillofac Oral Surg 2016; 15: 67-71.

30. Al-Dajani M. Can preoperative intramuscular single-dose dexamethasone improve patient-centered outcomes following third molar surgery? J Oral Maxillofac Surg 2017; 75: 1616-26.

31. Lim D, Ngeow WC. A comparative study on the efficacy of submucosal injection of dexamethasone versus methylprednisolone in reducing postoperative sequelae after third molar surgery. J Oral Maxillofac Surg 2017; 75: $2278-86$.

32. Zandi M. Comparison of corticosteroids and rubber drain for reduction of sequelae after third molar surgery. Oral Maxillofac Surg 2008; 12: 29-33.

33. Graziani F, D'aiuto F, Arduino PG, Tonelli M, Gabriele M. Perioperative dexamethasone reduces post-surgical sequelae of wisdom tooth removal. A split-mouth randomized double-masked clinical trial. Int J Oral Maxillofac Surg 2006; 35: 241-6.

34. Üstün Y, Erdoğan Ö, Esen E, Karsli ED. Comparison of the effects of 2 doses of methylprednisolone on pain, swelling, and trismus after third molar surgery. Oral Surg Oral Med Oral Pathol Oral Radiol Endod 2003; 96: 535-9.

35. Claseman TS, Foley WL, Davis RD, Morrison JW, Palmore CA, Murchison DF. A clinical evaluation of the analgesic efficacy of preoperative administration of ketorolac and dexamethasone following surgical removal of third molars. Anesth Prog 1998; 45: 110-6.

36. Buyukkurt MC, Gungormus M, Kaya O. The effect of a single dose prednisolone with and without diclofenac on pain, trismus, and swelling after removal of mandibular third molars. J Oral Maxillofac Surg 2006; 64: 1761-6.

37. Moore PA, Brar P, Smiga ER, Costello BJ. Preemptive rofecoxib and dexamethasone for prevention of pain and trismus following third molar surgery. Oral Surg Oral Med Oral Pathol Oral Radiol Endod 2005; 99: E1-7.

38. Peterson LJ, Ellis E, Hupp JR, Tucker MR. (eds), with six contributors. Contemporary oral and maxillofacial surgery: St Louis, C. V. Mosby, 1988

39. Montgomery MT, Hogg JP, Roberts DL, Redding SW. The use of glucocorticosteroids to lessen the inflammatory sequelae following third molar surgery. J Oral Maxillofac Surg 1990; 48: 179-87.

40. Hong SL, Levine L. Inhibition of arachidonic acid release from cells as the biochemical action of anti-inflammatory corticosteroids. Proc Natl Acad Sci U S A 1976; 73: 1730-4.

41. Hargreaves KM, Costello A. Glucocorticoids suppress levels of immunoreactive bradykinin in inflamed tissue as evaluated by microdialysis probes. Clin Pharmacol Ther 1990; 48: 168-78.

42. Montgomery MT, Hogg JP, Roberts DL, Redding SW.The use of glucocorticosteroids to lessen the inflammatory sequelae following third molar surgery. J Oral Maxillofac Surg 1990; 48: 179-87.

43. UStün Y, Erdogan O, Esen E, Karsli ED. Comparison of the effects of two doses of methylprednisolone on pain, swelling, and trismus after third molar surgery. Oral Surg Oral Med Oral Pathol Oral Radiol Endod. 2003; 96: 535-9.

44. Aziato L, Adejumo O. An ethnographic exploration of postoperative pain experiences among Ghanaian surgical patient. J Transcult Nurs 2015; 26: 301-7. 